\title{
An Analysis of Students' Ability in the Use of Simple Past Tense by Implementing Mistake Buster Technique
}

\author{
Rosalia Lero Kaka ${ }^{1}$, I Nyoman Suparwa ${ }^{2}$, Made Sri Satyawati ${ }^{3}$ \\ oncuroli@gmail.com \\ Udayana University, Denpasar 80114, Indonesia
}

\begin{abstract}
This study is aimed at examining (1) the effectiveness of applying the Mistake Buster technique in improving the Senior High School students' English ability to use the Simple Past Tense; (2) to identify the process of English teaching and learning in applying the Mistake Buster technique to improve the English ability of 20 students in a Senior High School to use the Simple Past Tense. This research was an experimental research with the quantitative method. The Mistake Buster technique was the independent variable (x) and the students' English ability in the use of Simple Past Tense was the dependent variable (y). Moreover, the techniques of data collection were the test, questionnaire, and observation. The tests were given twice for the Pre-test and Post-test. The questionnaire was given after the post-test, and observation was conducted while giving the treatment to the class. The results showed that the Mistake Buster technique can improve the students' English ability in the use of Simple Past Tense. It was proven by the improvement of students' mean scores that the score for pre-test was 48 improved to 82 at post-test score. The low score of students pre-test caused by lack of knowledge towards the use of positive, negative, and interrogative Simple Past Tense for both nominal and verbal sentence. Moreover, the hypothesis testing by the use of Paired Sample Test which revealed that the T-test was 9.292 which was showing the Ha was accepted. Based on the significance score ( 2 tailed), which was 0.000 proved Ha was accepted. Moreover, the application of the Mistake Buster technique in the learning process is considered to have a positive effect on increasing the ability to understand the Simple Past Tense. Based on the results of observations and questionnaires that $85 \%$ of students considered the Mistake Buster technique in good and very good categories.
\end{abstract}

Published by IJRP.ORG. Selection and/or peer-review under responsibility of International Journal of Research Publications (IJRP.ORG)

Keywords: Mistake Buster Technique, Simple Past Tense, Students’ Ability

\section{Introduction}

English is the language used to ascertain communication in the international ring. English is either as a first language, a second language, or as a foreign language. This is predisposed by the language status of English as a Lingua Franca. The Lingua Franca is a language that is largely used as a means of communication involving speakers who have a different first language (not English), those speakers using English as a second language (Harmer, 2001: 1). In learning English as a foreign language in Indonesia, one of the vital skills 

is the skills that are closely related to the language system both verbal and nonverbal, and it prioritizes the knowledge required to understand and convey exactly the natural meaning of utterances. Therefore, grammar is a crucial component to be understood by students who are learning it because acknowledging English grammar, it will be easier for students to write sentences accurately and acceptably based on its standard. in addition, tenses are grammatical categories that describe the time and situation of an event (Greenbaum \& Nelson, 2002: 70).

Related to the importance of English grammar, understanding the Simple Past Tense is a necessitate for 1st-grade high school students. Mastering the tenses in learning English might become guidance for students to understand the forthcoming learning matter, such as writing texts as an instance. However, based on an observation made to the 1st-grade students in a Senior High School in East Nusa Tenggara province, students were found having difficulties mastering the Simple Past Tense in the sentences. The thing that may affect the student's obstacles to understand and comprehend the Simple Past Tense was a low motivation exposed by the students in participating in learning as a prerequisite for students to learn English grammar. Therefore, the English learning process acquires prioritization of appropriate learning techniques to help students be more active throughout the learning process.

The Mistake Buster, yet, is believed as a grammatical learning technique that emphasizes the ability of students to discover grammatical errors contained in the text provided by the teacher. According to Huyn (2003: 1), the Mistake Buster is a very effective technique applied in directing students to be actively involved and responsible for learning by practicing to correct the inaccurate sentences provided by the teacher or learning mentor. In line with the efficacy of the Mistake Buster technique, Ratminingsih (2007), Amin (2015), and Syam (2017), in their preceding study, had proven that the implementation of Mistake Buster techniques is efficient to improve the English learning accomplishment of Junior High School students.

Therefore, based on the previous studies and phenomena found, this study examines the effectiveness of applying the Mistake Buster technique and identifies the teaching and learning process in applying the Mistake Buster technique to improve the ability to use Simple Past Tense.

\section{Theoretical Framework}

The theory used in this study is an elaboration of the opinions expressed by quite a few experts, especially in the field of linguistic error analysis. In this section, several theories form the basis of this research, however, the behavioristic theory of language learning is the major theory.

\subsection{Language Learning Theory}

Learning refers to conscious knowledge of the language and its rules. Learners know the rules, master the grammar, and can talk about them. Formal knowledge of the language or the learning process can be explicitly associated with the term learning (Purwo, 1990: 85). Language learning is generally based on four key concepts: language, learning, teaching, and context. (1) language learning requires a context about the nature of language. (2) language learning requires views and insights about the learner and the nature of language learning, (3) language learning implies views on language teaching and language teaching. (4) language learning occurs in certain contexts. Language, learning, and teaching must always be viewed from the context of one background and background (Wicaksono, 2016:1).

Language learning involves at least three disciplines, namely linguistics, psychology, and pedagogy. Linguistics provides information about languages in general and specific languages. Psychology describes how people learn things. Pedagogy (educational science) allows us to combine all information from (a) and (b) into one approach, method, and technique that is appropriate and used to facilitate the language learning process, especially in learning a second or foreign language (Wicaksono, 2016: 1) 
Language learning can be related to the terms approach, method, and technique. Brown (2001: 16-16) asserts that the approach is a theory about the nature of a language, the nature of language learning, and its application in education. The method is a series of teaching tools used to achieve a learning goal, the method also tends to be tied to the roles and behavior of teachers and students, tied to linguistic aspects, learning materials, learning sequences, and learning objectives. Moreover, techniques are various kinds of exercise activities in language learning to achieve learning objectives.

A teaching method can be effective if the preferred learning outcomes can be achieved with an appropriate method selected. Thus, the teaching-learning technique can be said to be successful if a teacher can see the conditions and situations of students and the learning tools used. Learning activities for students with moderate abilities are different from students' intellectual abilities. The lecture method, for example, will be less effective to be applied in a class with a large number of students. For various reasons that some students might pay less attention to the teacher's instructions, talk to their friends, the teachers' role to control or supervise students would be less than optimal.

\subsection{Behavioristic Teaching Theory}

Behavioristic learning theory explains that learning is a change in behavior that can be observed, measured, and assessed concretely. Change occurs through stimuli (stimulants) that causes a reactive behavior relationship (response) based on mechanistic laws. Stimulants are none other than the child's learning environment, both internal and external, which is the cause of learning. However, the response is the result or impact, in the form of a physical reaction to stimuli. Learning means strengthening bonds, associations, traits, and tendencies of Stimulus-Response behavior. The characteristics of behavioristic theory: 1) emphasize environmental factors, 2) emphasize visible behavior using objective methods, 3) are mechanical, and 4) emphasize the past.

Skinner (1975) explained that the necessary element in learning is reinforcement. The point is that the knowledge could be formed through the bond of stimulus-response, which would be stronger if it is given reinforcement. These reinforcements are positive and negative. Positive reinforcement could be in the form of gifts, behaviors, or rewards given by teachers or learning instructors. Forms of negative reinforcement include delaying or not giving rewards, giving additional assignments, or showing displeased behavior. In line with that, Skinner (1975) provides several principles, including; a) learning outcomes must be immediately notified to students if wrong is corrected, and the reinforcement must be given if correct; $b$ ) the learning process must follow the rhythm of the learners; c) giving lessons, use the module system; d) avoiding the punishment in the learning process, for that, the environment needs to be changed, to avoid punishment; e) in the learning process, activity is more important; f) the behavior that educators want is rewarded; g) learning to use shaping.

\subsection{Mistake Buster Technique}

The Mistake Buster technique was first tried by Huynh in 2003, it was found quite effective for preparing language learning activities. In its practice, the learners take over the role for correcting the mistakes provided by the teacher, while the teacher plays the role of the error maker. Thus, the mistake buster is an English teaching-learning technique that is to help students learn recovered by creating more opportunities. By providing more changes, students can reflect on everything they have learned and see things from different perspectives (Huynh, 2003).

The learning process using the Mistake Buster technique consists of the preparation stage and the implementation stage. In the preparation part, the teacher chooses the category of errors that will become the learning topic. At the implementation stage, the teacher will tell students to do a simple past tense review. Next, the class is divided into two groups, and told them to compete. For the instruction, the teacher asks students to fill in the left column with verbs and sentences in the Simple Present Tense form. After writing the 
Simple Present Tense sentences, students are then instructed to write the Simple Past Tense form of the verb and the sentence. They have to lift the hand quickly, and those who answer correctly, get a score of 10. Start the activity and add up the scores for each team. After all the verbs and sentences have been changed in the form of Simple Past Tense, then the teacher has to correct the students' work, the teacher will give rewards for the student's work and provide additional explanations if necessary.

\section{Research Method}

This study uses a quantitative method that aims to emphasize the purpose of measurement in the numerical analysis of data collected through tests, questionnaires, and observations. Quantitative research focuses on collecting numerical data and generalizing it across groups of people. Therefore, in this study, the researcher focused on using quantitative methods. This quantitative is determined in experimental research, especially the One Group Pretest-Posttest Design. In this design, the researcher chose the 20 students in a senior high school in East Nusa Tenggara province as the experimental group. The researcher gave a test to the class to get data. The Mistake Buster technique is considered as an independent variable (variable $\mathrm{x}$ ) while the students' ability to use and understand the Simple Past Tense is the dependent variable (variable y).

Based on the research procedures, the researcher gave a basic ability test (pre-test) to the students who had been selected as samples in the study. The results of the pre-test test were used to find out students' learning difficulties in understanding and using Simple Past Tense sentences. Furthermore, the difficulties faced by students would be categorized as students' needs analysis so that the researcher can provide action or treatment by utilizing learning materials, facilities, and as supporters in applying the Mistake Buster technique to improve the ability to understand and use the Simple Past tense.

\section{Result and Discussion}

In this section, the research data are presented based on the students' learning outcomes gained before applying the Mistake Buster technique, namely the pre-test, and the students' English learning outcomes after implementing the Mistake Buster technique, namely the post-test. In this case, the two forms of tests were given to students in the form of 48 multiple-choice questions. The number of test questions is divided into verbal and nominal sentences types with 24 items for each. This study was also conducted to determine how effective is the implication of the Mistake Buster technique to improve students' ability to understand the Simple Past Tense.

\section{A. Pre-test}

The Pre-test was given to find out students' learning difficulties in understanding and using Simple Past Tense sentences before applying the Mistake Buster technique. The table bellow presented the result of students' pre-test.

Tabel 1. Students' Learning Outcome of Pre-test

\begin{tabular}{|c|c|c|c|c|c|}
\hline \multirow{2}{*}{ No } & \multicolumn{2}{|c|}{ Sentences Type } & \multirow{2}{*}{$\Sigma$} & \multirow{2}{*}{ Score } & \multirow{2}{*}{ Category } \\
\hline & Verbal & Nominal & & & \\
\hline 1 & 5 & 9 & 14 & 29 & Very low \\
\hline 2 & 13 & 11 & 24 & 50 & Low \\
\hline 3 & 10 & 8 & 18 & 38 & Very low \\
\hline 4 & 17 & 21 & 38 & 79 & Good \\
\hline 5 & 8 & 10 & 18 & 38 & Very low \\
\hline 6 & 16 & 16 & 32 & 67 & Fair \\
\hline 7 & 15 & 15 & 30 & 63 & Fair \\
\hline 8 & 7 & 18 & 25 & 52 & Low \\
\hline 9 & 14 & 15 & 29 & 60 & Fair \\
\hline
\end{tabular}




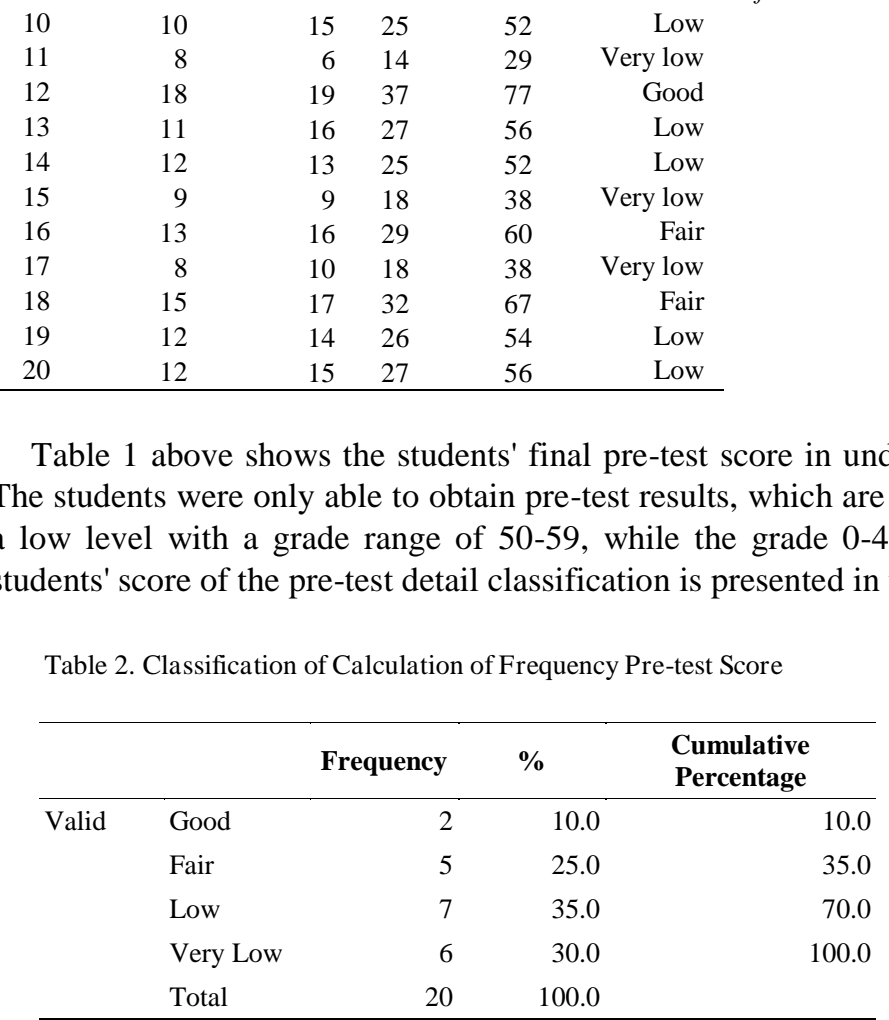

Based on the category of calculation of the frequency of pre-test scores presented in Table 2 above, it can be seen that students tend to have scored with low levels as many as 7 (35\%) of 20 students. In addition, at a very low level, there were $6(30 \%)$ of 20 students. Students with fair value category were $5(25 \%)$ students and there were only $2(10 \%)$ of 20 students who have a good category in understanding the use of the Simple Past. The pre-test result above showed that the students' ability is still below the average to understand the use of Simple Past Tense sentences. The students' levels of understanding of Simple Past Tense sentences, both in the form of verbal and nominal, showed that they were not only difficult to know how to formulate the forms of these sentences, but they also found it hard to master the past tenses for regular and irregular verbs.

\section{B. Post-test}

The post-test was given to the same class to determine the impact on students' English abilities in understanding and using the Simple Past Tense after applying the Mistake Buster technique. The treatment given to students after the pre-test is not to be discussed questions given in the pre-test but a simple past tense learning process by applying the Mistake Buster technique. Furthermore, as in the pre-test, the students were also given a multiple-choice test with the same number of questions. Thus, to find out the final score as a result of student learning after the Mistake Buster learning technique is applied in the classroom, the following is the final score of students based on the post-test results in understanding the use of Simple Past Tense sentences. 


\begin{tabular}{rrrrrr}
\hline \multirow{2}{*}{ No } & \multicolumn{2}{c}{ Sentences Type } & \multirow{2}{*}{$\boldsymbol{\Sigma}$} & Score & \multicolumn{1}{c}{ Category } \\
\cline { 2 - 3 } & Verbal & Nominal & & & Good \\
\hline 1 & 20 & 18 & 38 & 79 & Fair \\
2 & 16 & 17 & 33 & 69 & Very Good \\
3 & 21 & 20 & 41 & 85 & Very Good \\
4 & 20 & 22 & 42 & 88 & Good \\
5 & 18 & 18 & 36 & 75 & Very Good \\
6 & 17 & 22 & 39 & 81 & Good \\
7 & 18 & 20 & 38 & 79 & Very Good \\
8 & 21 & 20 & 41 & 85 & Fair \\
9 & 17 & 16 & 33 & 69 & Very Good \\
10 & 21 & 20 & 41 & 85 & Very Good \\
11 & 18 & 22 & 40 & 83 & Good \\
12 & 18 & 19 & 37 & 77 & Very Good \\
13 & 18 & 21 & 39 & 81 & Good \\
14 & 17 & 21 & 38 & 79 & Very Good \\
15 & 19 & 22 & 41 & 85 & Very Good \\
16 & 22 & 21 & 43 & 90 & Very Good \\
17 & 21 & 20 & 41 & 85 & Very Good \\
18 & 23 & 21 & 44 & 92 & Very Good \\
19 & 22 & 23 & 45 & 94 & Good \\
20 & 19 & 18 & 37 & 77 & \\
\hline
\end{tabular}

Table 3 above exposes the final post-test scores of students in understanding and using the Simple Past Tense that students can achieve post-test results which are classified as fair with a score range of 60-69, a good category with a score range of 70-79, while the range of 80-100 is categorized very good. More details, as revealed in the following table.

Table 4. Classification of Calculation of Frequency Post-test Score

\begin{tabular}{llrrr}
\hline & Frequency & \multicolumn{1}{c}{$\%$} & $\begin{array}{l}\text { Cumulative } \\
\text { Percentage }\end{array}$ \\
\hline Valid & Very Good & 12 & 60.0 & 60.0 \\
& Good & 6 & 30.0 & 90.0 \\
& Fair & 2 & 10.0 & 100.0 \\
& Total & 20 & 100.0 & \\
\hline
\end{tabular}

Based on the category of calculating the frequency of post-test scores presented in Table 4 above, the students' abilities tend to increase with the category of very good scores as many as 12 (60\%) of 20 students. Furthermore, in the good category as many as $6(30 \%)$ of 20 students. Moreover, there were only $2(10 \%)$ of the 20 students who were in a fair category in an understanding of the Simple Past Test. Based on the case above, the students are not very capable of mastering word classes such as adjectives or verbs. Furthermore, the students also have not been able to master several forms of past verbs, both regular and irregular. However, the Mistake Buster technique applied can significantly improve the mastery of the Simple Past Tense grammatical formulation and improve the mastering of word classes, past tense verbs, past tense adverbs, and past tense auxiliary verbs as evidenced by the post-test results. The improvement in the quality of understanding and the ability to use Simple Past Tense sentences is proven from the results of calculations based on the hypothesis described below. 
C. Prerequisite tests

Before doing the hypothesis testing, the data obtained must first be tested whether the data meets the requirements to proceed to hypothesis testing. Prerequisite tests that must be met include normality and homogeneity tests.

\section{a. Normality Testing}

The normality test of the data distribution used in this study uses the SPSS 16.0 for Windows software application, the test criteria at a significance level of 5\%, namely if the value of sig. $>=0.05$, then the data is distributed normally and vice versa if the value of sig. $=0.05$ means that the data is not distributed normally. The recapitulation of the results of the normality test is presented in the following table 5.

Table 5. Normality Test

\begin{tabular}{lcccccr}
\hline Value & \multicolumn{3}{c}{ Kolmogorov-Smirnov } & \multicolumn{3}{c}{ Shapiro-Wilk } \\
\cline { 2 - 7 } & Statistic & df & Sig. & Statistic & df & \multicolumn{1}{c}{ Sig. } \\
\hline Pre-test & .148 & 20 & $.200^{*}$ & .955 & 20 & .452 \\
Post-test & .128 & 20 & $.200^{*}$ & .966 & 20 & .659 \\
\hline
\end{tabular}

a. Lilliefors Significance Correction

*. This is a lower bound of the true significance.

Based on the normality testing between the pre-test and post-test values in the table above, the significance value showed that both pre-test and post-test were distributed normally because the test value of 0.200 is greater than 0.05 ( $\mathrm{sig}$. $>\alpha=0.05$ ).

b. Homogeneity Test

The homogeneity test was conducted to show that the differences obtained by the hypothesis test came from the differentiation between groups not caused by differences within groups. To test the homogeneity of variance of the two groups, the SPSS 16.0 for Windows software application was used. In this case, to determine the significant level, it must be based on the basic assumption that if the value of Sig $>\alpha=0.05$ then the hypothesis is accepted or the data can be said to be homogeneous. The recapitulation of the homogeneity test results can be seen in the following table 6.

Table 6. The Homogeneity Variance Testing

\begin{tabular}{lcrrrr}
\hline Research Variable & Levene Statistic & df1 & df2 & Sig. \\
\hline Pre-test - Post-test & .311 & 1 & 38 & .509 \\
\hline
\end{tabular}

Based on the data from the homogeneity test results in the pre-test and post-test values in the table above, the significance value based on the results of the homogeneity variance test shows that the two data variables tested are said to be homogeneously distributed because the test value 0.509 is higher than 0.05 (sig. $>\alpha=0.05)$.

c. Hypothesis Testing

Hypothesis testing in this study was conducted using the Paired Sample T-Test. Based on the basis for deciding on the test, if the significance value (2-tailed) is $<0.05$, then Ho is rejected, and Ha is accepted. On the other hand, if the significance value (2tailed) $>0.05$, then $\mathrm{HO}$ is accepted, and Ha is rejected. The results of hypothesis testing are presented in the following table 7. 


\begin{tabular}{lrrrrrr}
\hline & Mean & Std. Deviation & $\begin{array}{c}\text { Std. Error } \\
\text { Mean }\end{array}$ & t & df & Sig. (2-tailed) \\
\hline Pretest - posttest & -3.1 & 14.72 & 3.29305 & 9.292 & 19 & .000 \\
\hline
\end{tabular}

The results of hypothesis testing using the Paired Sample T-test as presented in the table above, the ttest value of 9.292 is higher than the t-table value of 1.724, which indicates that $\mathrm{Ha}$ is accepted and $\mathrm{H} 0$ is rejected. In addition, based on the significance value ( 2 tailed) of 0.000 less than 0.05 (sig. 2 tailed $<0.05$ ) also proves that $\mathrm{Ha}$ is accepted and $\mathrm{Ho}$ is rejected. Based on the decision-making requirements above, the initial abilities of students before being given treatment in the form of the application of the Mistake Buster teaching technique and abilities after being given treatment can be said to be significantly different.

\section{The Mistake Buster Technique Implementation}

The researcher gave questionnaires statements to students to find out how their assumptions or opinions regarding the implementation of the Mistake Buster. In this case, students' responses to the statements contained in the questionnaire were categorized on a Likert measurement scale ranging from strongly agree, agree, moderately, disagree, and strongly disagree. The results recapitulation of student answers based on 20 statements in the questionnaire regarding the implementation of the Mistake Buster technique is as follows.

Table 8. The Output of Questionnaire Given

\begin{tabular}{llrrr}
\hline & Frequency & Percent & Cumulative Percent \\
\hline Valid & Very Good & 4 & 20.0 & 20.0 \\
& Good & 13 & 65.0 & 85.0 \\
& Fair & 3 & 15.0 & 100.0 \\
& Total & 20 & 100.0 & \\
\hline
\end{tabular}

The results of student statements regarding the questionnaire on the implementation of the Mistake Buster technique, there are 4 (20\%) of 20 students think that the Mistake Buster is a very good technique. $13(65 \%)$ of 20 students stated that the Mistake Buster is a good technique to apply. Besides, there are 3 (15\%) other students who think the application of the Mistake Buster technique is categorized as fair.

Based on observations results, during the implementation of the Mistake Buster technique, the students had a higher motivation to discover new vocabulary items and to discuss in groups. It also proves that the improvement in learning motivation affects students' understanding ability in the use of the Simple Past Tense, which is also evidenced by the post-test results afterward. However, the students can also be said to have increased strength in writing sentences and pronouncing English sounds. In line with the student's activities in the learning process, the students were also more comfortable with the implementation of the Mistake Buster as an effective technique to improve their English language skills. This is evidenced by the questionnaire given by the researcher to determine students' perceptions of the application of the Mistake Buster technique.

\section{Conclusion}

Exploring the target language abilities possessed by students is very useful as an analysis of students' needs (need analysis) to determine teaching methods. The student's basic needs must be improved so that they are more precisely based on targets under the design of learning objectives. The Mistake Buster can be applied as an effective technique in increasing student motivation and ability to learn a target language, especially 
English. Moreover, the implementation of the Mistake Buster technique can achieve the students' abilities, especially for the senior high school to master the target language, especially English, which is not only done at school but can also be done independently. In addition, material development does not always have to go through the instructions given by the teacher but also departs from one's own will to develop.

\section{References}

Amin, B. 2015. The Use of mistake buster technique to improvethe students' writing skill. Exposure JournaL, 1(4).

Brown, H. D. 2001. Teaching by Principle an Interactive Approach to Language Pedagogy (Second Edition). San Fransisco: A Pearson Education Company.

Greenbaum, S. \& Nelson, G. 2002. An Introduction to English Grammar. Second Edition. London: Pearson Education Limited.

Harmer, J. 2001. The Practice of English Language Teaching ( $3^{\text {rd }}$ ed). Cambridge, UK. Longman.

Huynh, H. K. P. 2003. Getting Students Actively Involved Using Mistake Buster. The Internet TESL Journal. Vol. 2.

Purwo, B. K. (1990). Pragmatik dan Pengajaran Bahasa. Surakarta. Yuma Pustaka.

Ratminingsih, Ni Made. 2007. Teknik Mistake Buster dalam Pembelajaran Gramatika Siswa Kelas I SMP Negeri Sukasada. Jurnal Pendidikan Undiksa. 139(1).

Skinner, B. F. 1976. About Behaviorism. New York: Vintage Books.

Syam, A. T. 2017. Using the Mistake Buster Technique to Improve The English Grammar Mastery. IJENTAL, $1(2)$.

Tarigan, H. D. 1992. Pengajaran Analisis Kontrastif Bahasa. Bandung: Angkasa.

Wicaksono, A., \& Ahmad S. R. 2016. Teori Pembelajaran Bahasa (Suatu Catatan Singkat). Yogyakarta: Garudhawaca. 